\title{
Survival in a long-lived territorial migrant: effects of life-history traits and ecological conditions in wintering and breeding areas
}

\author{
Juan M. Grande, David Serrano, Giacomo Tavecchia, Martina Carrete, Olga Ceballos, \\ Ricardo Díaz-Delgado, José L. Tella and José A. Donázar
}

J. M. Grande (manu.grande@usask.ca), Dept of Biology, Univ. of Saskatchewan, 112 Science Pl., Saskatoon, SK, S7N 5E2, Canada. - D. Serrano, M. Carrete, O. Ceballos, R. Díaz-Delgado, J. L. Tella and J. A. Donázar, Dept of Conservation Biology, Estación Biológica de Doñana (CSIC), Avda. M. Luisa s/n, ES-41013, Seville, Spain. - G. Tavecchia, Inst. Mediterrani d’Estudis Avançats (CSIC),Carrer Miquel Marqués 21, ES-07190, Esporles, Spain.

\begin{abstract}
Despite its key role in population dynamics and evolutionary ecology, little is known about factors shaping survival in long-lived territorial species. Here, we assessed several hypotheses that might explain variability in survival in a migratory Spanish population of a long-lived territorial species, the Egyptian vulture Neophron percnopterus, using a 16-year monitoring period and live-encounter histories of 835 individually marked birds. Cormack-Jolly-Seber capture-recapture models showed no evidence for effects of sex or nestling body condition on survival. However, the normalized difference vegetation index (NDVI; an indicator of primary productivity) of natal territories had positive effects on juvenile survival, indicating that environmental conditions experienced early in life can determine survival prospects. Survival increased with age (0.7390.02 in the first 2 years to 0.7890 .03 in years 3 and 4$)$ to later decrease when birds were five years old (0.6090.05), the age at which they acquire the adult plumage, abandon the communal lifestyle of juveniles, and may look for a breeding territory. At older ages, survival was higher for non-breeding (0.7590.02) and breeding adults (0.8390.02). Among the latter, birds that recruited into better territories had higher survival prospects. Age-specific variation in survival in this species may be related to behavioural changes linked to dispersal and recruitment into the breeding population, while survival prospects of adult birds strongly depend on breeding territory selection. These results suggest a tradeoff between recruiting soon, and thus reducing mortality costs of a long and extensive dispersal period, and trying to recruit into a good quality territory. Finally, annual survival rates for birds of all age classes were positively related with the NDVI in their African wintering grounds. Although this relationship was probably mediated by food availability, further research is needed to properly identify the limiting factors that are affecting trans-Saharan migrants, especially in light of global climate change.
\end{abstract}

Survival rate is one of the principal demographic parameters determining population growth rates in living organisms. Therefore, how ecological constraints and life-history traits shape its variability is a central question in population ecology (Lebreton et al. 1992, Sæther and Bakke 2000). Besides, a properly understanding of survival variability may shed light on the possible costs of certain behavioural strategies (e.g. the tradeoff between current and future reproduction), or to ascertain which selective forces may be operating over a population, thus being also crucial for both behavioural and evolutionary ecology (Stearns 1992). Despite its relevance, survival was not a well studied demographic parameter in wild populations just a decade ago (Sæther and Bakke 2000). In the last ten-fifteen years, the wide development of easily accessible statistical tools and the increase in the number of medium- or long-term monitoring programs has multiplied the number of studies on the topic (Harris et al. 1992, Spear and Nur 1994, van
Tavecchia et al. 2001, 2008, Serrano et al. 2005). Among them, studies of long-lived species were mainly centred on social species such as ungulates or colonial seabirds and waterbirds, which gregarious habits make them relatively easy to monitor (Harris et al. 1992, Spear and Nur 1994, van der Jeugd and Larsson 1998, Coulson et al. 2001, Tavecchia et al. 2001, 2008). In contrast, most long-lived birds breed solitarily in wide territories far apart and are difficult to capture and monitor (Newton 1979), so that long-term and large-scale data sets of relatively long-lived individually marked territorial birds are still highly underrepresented (but see Franklin et al. 2000, Altwegg et al. 2003, Kauffman et al. 2003, Reid et al. 2006).

In long-lived species, survival rates are expected to follow a non-linear pattern along the lifespan according with different constraints and selective pressures. A combination of the genetic heritage and the particular environment in which a bird is raised (e.g. rich or poor habitat, large or 
quality (e.g. immune function, body mass). Survival of fledglings will then be shaped by selective forces acting over the variation of such quality (Newton 1979, Lindström 1999). Depending on the strength of the stress factors faced by the individuals (e.g. food availability, disease, adverse climatic weather) selective forces will act at the nest through brood reduction (Donázar 1993, Mauck et al. 2004), over the individuals during the first months after fledgling (Newton 1979), or will affect the individuals along their entire life (van de Pol et al. 2006, Reid et al. 2006). In subsequent years, immature birds may wander over extensive feeding grounds, settle during variable temporal periods in suitable areas, or perform long trips prospecting for potential breeding sites, especially when approaching the age of first breeding (Reed et al. 1999). Survival of floaters through this critical dispersal period may have a strong impact on population dynamics (Gaillard et al. 1998, Penteriani et al. 2005). However, the spatial and behavioural ecology of floaters is poorly understood, and thus it is hard to assess how a variety of factors acting on nonbreeding grounds are shaping their survival. The first years of adulthood, when birds have to find a territory, competing with older and more experienced individuals and drastically changing their resource allocation to reproduce, may impose additional costs in terms of survival (Conover et al. 2000, Tavecchia et al. 2001). Finally, after recruiting into the breeding population, survival may increase slowly or remain constant until senescence, although sexual asymmetrical costs of reproduction (Breitwisch 1989, Tavecchia et al. 2001) or spatial heterogeneity in the quality of breeding territories (Franklin et al. 2000, Sergio and Newton 2003, Carrete et al. 2006) may introduce additional variability.

In this study, we take advantage of a long-term study (16 years) in a Spanish population of Egyptian vultures Neophron percnopterus to analyse within a capture-markrecapture analytical framework (CMR, Lebreton et al. 1992) how life-histories and phenotypic traits, habitat heterogeneity and environmental variability affect the survival of a long-lived species. Egyptian vultures can live up to 37 years in captivity (del Hoyo et al. 1994) and at least 21 years in the wild (Grande et al. unpubl.). In continental Europe the species is migratory. All Spanish birds depart in late summer to their African wintering areas in the Mauritanian Sahel region (southern third of Mauritania and adjacent areas of Senegal and Mali; unpubl.). In spring, adults return to breed first, from early March onwards while immature birds return later in the season. Most young birds seem to return from Africa for the first time at two or three years of age (Donázar 1993). This cliff-nesting vulture actively defends a territory around the nest, but can be gregarious when feeding or roosting outside breeding territories (Donázar 1993). During the immature stage, at least while in Europe, Egyptian vultures exhibit a relatively 'easy' lifestyle, visiting predictable food sources and gathering in communal roosts of up to 200 individuals, which are sparsely situated through the breeding grounds (Donázar 1993, Grande 2006). This fact enables a direct monitoring of the non-reproductive population during this part of the year. This species has severely declined through the last decades all across its European range (BirdLife International 2004). In Spain, this decline was produced mainly by human persecution and general habitat degradation (Carrete et al. 2007). However, almost nothing is known about its wintering ecology, and thus, on the factors limiting its populations in Africa.

According to the life-history and ecological characteristics of the species we made a series of predictions about variables potentially affecting survival (Table 1):

1. Ontogenic conditions. The variability among individuals in the conditions experienced during development will be reflected in their condition at fledgling, which in turn determines their survival prospects (Magrath 1991, Harris et al. 1992, Spear and Nur 1994, van der Jeugd and Larsson 1998). Body mass at fledging may vary up to $20 \%$ over the mean in Egyptian vultures, and thus we expected a positive effect of body mass on survival probability.

2. Age and sex. (a) Egyptian vultures face four different stages during their lives which can be associated with different survival probabilities: 1 ) during the juvenile stage (from fledgling to 2 years old), fledglings migrate for the first time to Africa and spend a

Table 1. Hypotheses, predictions, and associated model notation for survival of Egyptian vultures in the Ebro Valley population. Note that the sign of the slope expected under each prediction in models including covariates is shown.

\begin{tabular}{|c|c|c|}
\hline Hypothesis & Predictions and expected results & Model \\
\hline $\begin{array}{l}\text { 1. Individual survival depends on } \\
\text { ontogenic characteristics }\end{array}$ & $\begin{array}{l}\text { Egyptian vultures with better body condition will } \\
\text { have higher survival; } \beta \text { bc }>0\end{array}$ & phi bc \\
\hline \multirow{2}{*}{$\begin{array}{l}\text { 2. a) Age-specific variation in survival } \\
\text { b) Survival changes depending on the sex of } \\
\text { the individual }\end{array}$} & Survival will increase with age classes & phi \\
\hline & There will not be sexual differences in survival & \\
\hline \multirow[t]{2}{*}{$\begin{array}{l}\text { 3. Individual survival depends on the quality of } \\
\text { the territory in which they were born or breed }\end{array}$} & $\begin{array}{l}\text { 1) Survival is higher for fledglings born in high quality } \\
\text { territories; } ß \text { NDVI terr and/or } ß \text { nbr fled }>0\end{array}$ & phi NDVI terr, nbr fled \\
\hline & $\begin{array}{l}\text { 2) Survival is higher for adults that recruited into } \\
\text { high quality territories; } \beta \text { NDVI terr and/or } \beta \text { nbr fled }>0\end{array}$ & err, nbr fled \\
\hline \multirow[t]{2}{*}{$\begin{array}{l}\text { 4. a) Survival depends on the availability of resources } \\
\text { in breeding and wintering grounds }\end{array}$} & $\begin{array}{l}\text { 1) Survival will be higher in years with high primary } \\
\text { productivity in the breeding population; } B \text { NDVI bre }>0\end{array}$ & phi NDVI bre \\
\hline & $\begin{array}{l}\text { 2) Survival will be higher in years with high primary } \\
\text { productivity in wintering grounds; } B \text { NDVI Afr }>0\end{array}$ & phi NDVI Afr \\
\hline $\begin{array}{l}\text { b) Survival depends on the intensity of } \\
\text { human persecution }\end{array}$ & $\begin{array}{l}\text { Survival will be inversely related to intensity of poison } \\
\text { used; } ß \text { po B0 }\end{array}$ & phi po \\
\hline
\end{tabular}

bc: body condition; ax: age class; nbr fled: mean number of fledglings raised in the territory; NDVI terr: NDVI in the territory; NDVI bre: NDVI in the breeding area; NDVI Afr: NDVI in the African wintering grounds; po: intensity of poisoning. 
minimum of one year in their wintering grounds; 2) during the immature stage (from 2 to 4 years old), young vultures migrate back to the breeding areas but have not reached sexual maturity yet and typically group with other immature birds (see above); once reached sexual maturity ( $>4$ years old), 3) during the non-breeding adult stage, individuals prospect large areas in search of a mate and a territory; and finally, 4) during the breeding adult stage, birds obtain a territory to which they usually return every year to breed (Donázar 1993). As in other long-lived species, we expected that survival probability should increase gradually with age as birds improve their skills and/or lower quality individuals are progressively eliminated from the population (Tavecchia et al. 2001). However, apparent survival could decrease to some extent during the adult non-breeding stage as a result of costs associated with territory search and acquisition, or due to permanent emigration from the study area. (b) The Egyptian vulture is almost sexually monomorphic and both sexes share parental duties and use the same wintering areas (Donázar 1993), so we expected survival to be independent of sex.

3. Quality of breeding territories. Egyptian vulture territories are heterogeneous with respect to both the availability of natural resources and the level of human pressure (Grande 2006, Carrete et al. 2007). The conditions experienced early in life can strongly affect individual quality, therefore individuals born in highquality habitats might have higher survival probability (Lindström 1999). According to the life-history theory, the best option for a long-lived parent is to keep its own survival high and its reproductive effort low if the environment is unpredictable (Hirshfield and Tinkle 1975). However, increasing evidence suggests that long-lived birds may compromise their own survival when faced with adverse environmental breeding conditions (Davis et al. 2005). Accordingly, adults recruited into poor quality territories should suffer high self-maintenance costs and pay reproductive effort by having lower survival.

4. Food supply and human persecution. (a) Egyptian vultures have an opportunistic scavenger diet that includes a significant proportion of domestic cattle carrions, but also small- and medium-sized wild prey (Donázar 1993). In Spain most cattle is stabled, and therefore cattle numbers do not properly reflect cattle availability for vultures. Further, there are no good estimates of this vulture's most important wild prey (i.e. the wild rabbit Oryctolagus cuniculus) to analyse its availability in our study area. However, breeding performance in our study area (Grande 2006), and territory persistence through Spain (Carrete et al. 2007) were positively correlated to an index of primary productivity, the normalized difference vegetation index (NDVI; Seoane et al. 2003). High primary productivity is associated with a high density of primary consumers, especially in arid environments (Holmgren et al. 2006). Therefore, food availability for the Egyptian vultures should be higher in years of high primary productivity. If food availability on the wintering grounds is a relevant survival constrain, we expect that survival probability of Egyptian vultures should be higher in years of high primary productivity in the wintering grounds. The same reasoning can be applied in the case of the primary productivity in the breeding grounds. (b) As a final predictor of the temporal variability of survival we considered the effect of human persecution. A significant factor determining the recent extinction of Egyptian vulture territories in Spain is the illegal use of poison for predators' control (Carrete et al. 2007) that unfortunately is a widespread practice in the country (Villafuerte et al. 1998). Hence, survival should be inversely related to the intensity of poison use in the breeding grounds.

As it is usual in capture-recapture studies, our analyses are correlative and thus cannot confirm causal effects. However, to try to test relevant hypotheses through long-term experimental studies is almost impossible when dealing with a longlived, threatened species that inhabit extensive areas and spend a significant part of its life in their wintering grounds. Besides, some environmental variables such as climate or primary productivity cannot be manipulated and therefore the assessment of their effects on survival can only be done through correlational studies. These correlational studies could then help to lend weight to specific initial hypotheses from which generalities may emerge, and which may subsequently inform focused experiments or monitored management regimes designed to rigorously test specific models of demographic variation (Sutherland 2000).

\section{Methods}

\section{Data collection}

We studied the Egyptian vulture population of the Ebro Valley in the Aragon and Navarra provinces (northeastern Spain). The population is distributed through $19000 \mathrm{~km}^{2}$ and has decreased from 194 pairs in 1979 to 94 in 2005 (Grande 2006).

We used data from individually marked vultures captured between 1990 and 2005; birds were marked with a metal and a plastic colour ring to be read from distance. Fledglings were marked in their nest, while immature and adults were captured with cannon nets in the surrounding of communal roosts and breeding territories. From 1995 onwards, following the loss of a variable number of the plastic rings (minimum annual loss rate of about $6 \%$ ), we used thicker rings (3.1 mm instead of $1.55 \mathrm{~mm})$. No ring losses were ever recorded after 1995. We accounted for this effect by including the type of plastic ring used (i.e. thin or thick) as an additive effect in the survival term of all models (below) and few recaptures of birds with metal ring only were excluded to reduce recapture heterogeneity. Since 1990 all known breeding territories were visited at least three times per year to record occupancy, reproductive success, and to mark the fledglings. Additionally, from mid July to late August, we also systematically inspect communal roosts and feeding points (vulture restaurants, rubbish dumps, etc.) in search of marked birds. Communal roosts are situated in three main 
areas in our study population and, contrary to the regular monitoring of breeding territories, have been monitored differently through the years. Therefore, we codified recapture effort into three categories according to the number of areas extensively monitored each year: low (one area monitored: 1991-1992, 1997-1999 and 2005), medium (two areas monitored: 1993, 1996 and 2000), and high effort (all three areas monitored: 1994-1995 and 2001-2004).

\section{Data sets}

We analysed individual mark-reencounter histories collected from 1990 to 2005. Given the presence of missing values for individual covariates in some histories, we used three different subsets according to the hypothesis of interest. The first subset (Sub-1) included birds marked as fledglings for which individual covariates were measured (below). This subset was structured in two groups according with the type of ring (thin or thick). The second subset (Sub-2) included all marked birds irrespective of age at marking. It was structured according to the age at which birds were marked (fledglings, 2,3 , 4, and $>4$ years old) and the type of ring. Finally, the third subset (Sub-3) included only data from breeding adults to focus inferences on the breeding population. This analysis was restricted to the period 1994 to 2005, because it provided the most comprehensive capture-mark-recapture data for marked adults.

\section{Predictors of survival}

Individual covariates

We considered age, sex and body condition of birds as predictors of survival and/or recapture probability. Bird age was assessed by plumage characteristics until the fifth year (Forsman 1999). Since 1995, birds were sexed by molecular techniques (Ellegren 1996). Finally, as a measure of body condition of fledglings, we used the standardized residuals of the regression of $\log$-body mass (925 g) on $\log -7$ th primary length $(\mathbf{9 1} \mathrm{mm})(0.000890 .039 \mathrm{SE}$, range: $-5.13-3.93)$.

\section{Quality of breeding territories}

Traditionally, the quality of a breeding territory has been linked with the resources that it contains (Johnson 2007). As suggested for other species (Schaub et al. 2005), the NDVI seems to be a good indicator of food availability for the Egyptian vulture (above). Therefore we used the NDVI value within a radius of $8 \mathrm{~km}$ around the nest (size of the home range of the species in our studied population; Grande 2006) as a surrogate of food-mediated quality in the year of birth for the Sub-1 data subset analysis. For adults (Sub-3), we used the arithmetic mean of the NDVI value in the territory over the period from 1986-2005. Average NDVI values for every territory (96.78910.9 SD, range: 74.69-125.38) were calculated by using the long time series of NDVI composite $1>1 \mathrm{~km}^{2}$ images available for Iberian Peninsula since 1986. However, some authors claim that as the root of the concept of habitat quality is demographic, when available, the best measure of habitat quality is the direct fitness output of that habitat (Johnson 2007). Therefore we also tested whether the mean productivity of the territory, i.e. the number of fledglings year $^{-1}$ of monitoring (0.9490.036 SE, range: $0-2)$, noted as nbrfled in CMR models, was a good predictor of survival for fledglings and breeding adults.

Temporal changes in environmental conditions

As a measure of resource variability at the scale of the entire breeding and wintering areas, we used the mean yearly value of the NDVI. For the breeding grounds, we used the yearly mean value of NDVI of the entire study area (mean value from September in year $t-1$ to June the year t, 96.7892.34 SE, range 80.75-109.52). For the wintering area we used the yearly value of the NDVI in a radius of $25 \mathrm{~km}$ around each location of seven vultures (two adults, two immature and three juveniles captured in northern, central and southern Spain) that were satellite-tracked at their wintering quarters during the 2002-2003 and 2003-2004 winters (41.7890.75 SE, range: 37.26-46.21). The NDVI composite images for the wintering grounds were obtained from the Advanced very high resolution radiometer (AVHRR) sensor from satellites of the US Natl Oceanic and Atmosphere Adm. (NOAA) available at the Africa Data Dissemination Service <http://earlywarning.usgs.gov/adds/> with a $64 \mathrm{~km}^{2}$ pixel area for the whole African continent.

Human persecution

As a surrogate of the intensity in illegal poison use, we used the annual number of poisoning episodes recorded in the study area from 1990 to 2004 (19.293.96 SE, range: 1-46). We considered as a poisoning episode each recorded poisoned bird, mammal, or bait. When more than one animal or bait was found in the same area within a month we considered them as a single episode (Whitfield et al. 2004). Poisoning data were obtained from the Antidote Program, a national campaign coordinated by WWFADENA to compile information on poisoning episodes, the wildlife rehabilitation centre of the Aragón Government, from Navarra environmental agents, and from our own recorded data.

\section{Analytical procedures}

Testing capture-recapture assumptions and modelling procedures

Basic assumptions of CMR models were assessed through goodness-of-fit tests using program U_CARE 1.4 (Choquet et al. 2002), which includes directional Z-tests designed to detect the presence of transients or the existence of factors generating 'trap dependence' effects (Appendix A in Tavecchia et al. 2008). CMR models were implemented using program MARK (White and Burnham 1999), which estimates survival and recapture probabilities using maximum-likelihood procedures (Lebreton et al. 1992). In the models phi denotes apparent survival, including permanent 

emigration, and $\mathrm{p}$ is the recapture probability. The symbol + denotes a statistical interaction between the main effects, while + is used for additive effects. Ring type (thin or thick) and age effects were denoted in the models as subscripts $r$ and ax respectively, where $\mathrm{x}$ is the age class considered. Continuous variables linked to individual traits were included as time-invariant individual covariates, while categorical variables were included as groups. Surrogates of general conditions or annual global features were included as temporal covariates. Subscripts used in model notation are specified in Table 1.

Model selection was based on the Akaike's information criterion corrected for small sample size (AICc, Burnham and Anderson 1998). Models were scored according to the differences in AICc values (DAICc) and relative support of each model (AICc weight). Models with the lowest AICc value were retained as the best compromise between a high proportion of deviance explained and a low number of parameters in the model.

In both, Sub-1 and Sub-2 data sets we modelled recapture from an initial model with six age classes, timedependent parameters within each age class, and an additive effect of ring, $r$, on survival (phi $(a 1$, a2, a3, a4, a5, a $>5$ ) $>t \neq r$ P $(a 1, a 2, a 3, a 4, \quad a 5, a>5)>t)$. We started modelling the general interaction of six age classes and time against a model with time additive effect (phi (a1, a2, a3, a4, a5, a>5) $>t \neq \mathrm{r}$ P (a1, a2, a3, a4, a5, a>5) $\neq \mathrm{t})$ and a model with recapture effort categorized (see above; phi (a1, a2, a3, a4, a5, a $>5$ ) $>t \neq \mathrm{t}$ p (a1, a2, a3, a4, a5, a>5) $\neq$ ). We then proceed to test for different age structures in recapture probability including a different value of recapture for birds marked as adults (regardless their breeding status) in Sub-2 (denoted as $g$ in models). Once a simpler structure for recapture probability was reached, we progressively eliminated non significant effects from the survival probability. First, we tested whether the effect of ring loss was constant through age classes (additive effect) or it varied with age (interaction effect). As it proved to be constant, we maintained it as an additive effect in the analyses. Finally, we tested hypotheses on individual and time-dependent sources of variation (Table 1). As the effect of body condition and quality of the natal territory can change with individual age, we tested their effects as an interaction with age, but also as an additive effect (a constant, long-term effect on individuals), and just as an additive effect for the first survival interval (affecting only juvenile survival).

To ensure that the effects we found were related to survival and not mediated by an effect on recapture probability, in the best-ranked models we interchanged the structure of survival and recapture probabilities. All the estimates of survival and recapture probabilities are provided 9 SE.

\section{Results}

\section{Goodness of fit and data heterogeneity}

Our general capture-recapture data set had 835 Egyptian vultures, of which 658 were captured as fledglings at their nests and 177 were captured with cannon nets as immature or adults (Table 2). The global goodness-of-fit test showed a lack of fit of the full time- and group-dependent model (phi ${ }_{(\mathrm{g}>\mathrm{t})} \mathrm{P}_{(\mathrm{g}>\mathrm{t})}$ ) for both the juvenile's data set (Sub-1; $\mathrm{x}_{136}^{2}=$ 419.3; p B 0.001) and the data set including all marked birds (Sub-2; $\mathrm{x}_{117}^{2}=454.33$; $\mathrm{p}$ B 0.001). A detailed analysis of the specific components of these tests showed that this lack of fit was mainly due to an age-dependent effect in birds marked as fledglings. A new model including a different parameter of survival for the year of capture for both groups of fledglings provided a good fit of the data $\left(\mathrm{x}_{63}^{2}=26.2801, \mathrm{p}=0.999\right.$ for Sub-1, and $\mathrm{x}_{98}^{2}=61.483$; $\mathrm{p}=0.999$ for Sub-2). In contrast, the goodness-of-fit test of a model including full time parameters in the group of breeding adults (Sub-3, $n=72$ ) suggested a good fit of the data $\left(\mathrm{x}_{20}^{2}=3.84 ; \mathrm{p}=1\right)$.

\section{Recapture probability}

The best model for recapture probability for Sub-1 included three age classes and the recapture effort (phi (a1, a2, a3, a4, a5, a>5) $>t \neq r \quad P(a 1, a 2, a>2) \neq e)$. This was also the retained model for Sub-2, although it included a separate value for birds marked as adults which were not

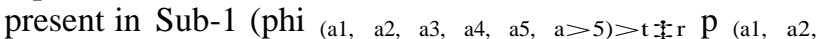
$a>2) \neq g \neq e$ ). According to this model, recapture probabilities increased with age and recapture effort. It was almost zero for first-year birds, increased substantially for secondyear and older birds, and was the highest for the group of birds captured as adults (Fig. 1). Finally, recapture probability for breeding adults was very high and constant (Sub-3; $\mathrm{p}=0.9490 .02$ ).

\section{Survival probability}

\section{Individual covariates}

For Sub-1, the best model included three age classes with a single value for the first two years, a second for the third and the fourth years, and a final one for five years onwards (model 5 in Table 3). A model with a similar AICc value (DAICc $=1.56$ ) included four age classes with different values for 5 and $>5$ years birds (model 4 in Table 3 ). Here, survival increases from a1-a2 to a3-a4, then decreases at five years, when birds acquire the full adult plumage, but recover from six years onward. When sample sizes of aged birds were increased by including immature and adult birds

Table 2. Number of individual Egyptian vultures banded per year and age category at the Ebro valley.

\begin{tabular}{|c|c|c|c|c|c|c|c|c|c|c|c|c|c|c|c|c|}
\hline Age & 1990 & 1991 & 1992 & 1993 & 1994 & 1995 & 1996 & 1997 & 1998 & 1999 & 2000 & 2001 & 2002 & 2003 & 2004 & Total \\
\hline Fledgling & 28 & 37 & 36 & 37 & 31 & 36 & 23 & 22 & 30 & 52 & 97 & 56 & 83 & 54 & 36 & 658 \\
\hline 2 year old & 0 & 4 & 3 & 4 & 5 & 0 & 0 & 0 & 0 & 0 & 0 & 0 & 10 & 1 & 4 & 31 \\
\hline 3 year old & 1 & 1 & 0 & 2 & 0 & 7 & 0 & 0 & 0 & 0 & 0 & 0 & 7 & 7 & 2 & 27 \\
\hline 4 year old & 0 & 0 & 1 & 6 & 1 & 7 & 0 & 0 & 0 & 0 & 0 & 0 & 11 & 7 & 0 & 33 \\
\hline Adult & 1 & 5 & 2 & 8 & 1 & 12 & 1 & 0 & 1 & 0 & 6 & 1 & 25 & 20 & 3 & 86 \\
\hline Total & 30 & 47 & 42 & 57 & 38 & 62 & 24 & 22 & 31 & 52 & 103 & 57 & 136 & 89 & 45 & 835 \\
\hline
\end{tabular}




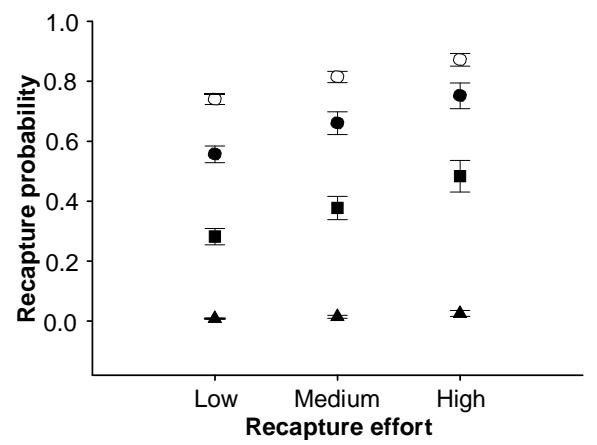

Figure 1. Recapture rates of Egyptian vultures at the Ebro Valley in relation to recapture effort (Sub-2). Estimates 9 SE at 1-year old (black triangles), 2-year old (black squares), 12-year old (black circles), and a separate value for birds captured for the first time with adult plumage (white circles) are shown.

captured with cannon nets (Sub-2 data set), the model with four age classes was clearly retained (model 12 in Table 4; Fig. 2), being three times more supported according to the AICc weights than the model with three age classes (model 13 in Table 4). The model interchanging the survival and recapture age structures (phi (a1, a2, a $>2) \neq \mathrm{g} \neq \mathrm{r} \quad \mathrm{p}$ (a1=a2, a3 $=$ a4, a5, a $>5) \neq_{e}$ ) was 193.34 AICc points higher thus supporting the robustness of this survival age structure.

Sexual differences in survival were tested with a subset of individuals sexed by molecular techniques (birds marked from 1995 onwards; $n=436$ ). The survival models including a sex effect were always rejected. For this reason the sex-effect was no longer considered. We did not detect an effect of fledgling body condition on survival (see model 7 in Table 3).

Breeding territory quality, temporal changes in environmental conditions and human persecution

The model including a positive effect of primary productivity in the natal territory at birth (NDVI terr) was strongly supported (12 times better according to the AICc weights than the model without that effect; DAICc $=5.1 ; \beta_{\mathrm{NDVI}}$ terr $=0.26590 .031$; models 9 and 5 in Table 3). The model interchanging survival and recapture structure (phi $(\mathrm{a} 1=\mathrm{a} 2, \mathrm{a} 3=\mathrm{a} 4, \mathrm{a}>4) \neq \mathrm{r} \mathrm{P}(\mathrm{a} 1, \mathrm{a} 2, \mathrm{a}>2) \neq \mathrm{NDVI}$ terr $)$ was 5.12 AICc points lower, confirming that the effect of NDVI terr was on survival and not on recapture.
For the whole sample of individuals (Sub-2), the best model obtained included the effect of primary productivity in African wintering grounds (NDVI Afr) as an additive effect (model 18; Table 4), being 133 times better than the same model without the NDVI Afr effect according to the AICc weights (model 12; Table 4). Survival tended to be higher in years of high primary production (high NDVI values) on wintering quarters ( $\left.\beta_{\mathrm{NDVI} \text { Afr }}=0.0890 .002\right)$ for all age classes (Fig. 3). This model had almost the same value than the unconstrained time model (model 22; Table 4 ), which suggests that temporal variations in survival in our studied population can be also explained by changes in primary productivity in Africa. Models including the primary productivity in the breeding area or the number of poisoning events were not retained (models 20-21 and 16-17 respectively; Table 4). The alternative model including the NDVI Afr effect on recapture had a DAICc value of 3.9 and was rejected.

Survival of breeding adults

The model retained for breeding adults included the additive effect of primary productivity in wintering grounds ( $\beta_{\text {NDVI Afr }}=0.2190 .06$ ), as well as the quality of the territory in which birds were recruited, estimated through demographic fitness $\left(\beta_{\text {nbr }}\right.$ fled $=0.4290 .19$; model 30, Table 5). This model was 4.5 times more supported than the next model according to the AICc weights. The model including the effect of nbr fled on recapture (instead of on

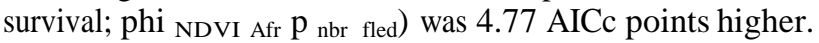
Mean breeding adult survival was 0.83390 .022 .

\section{Discussion}

\section{Life-history and survival rates}

Our results suggest that local survival rates of long-lived territorial species could be strongly constrained by behavioural strategies linked to the acquisition of a breeding territory. Egyptian vultures followed the general and predicted pattern of increments in survival as bird's age described for other long-lived species (Tavecchia et al. 2001), but with a sharp decline when birds are about five years old and abandon their easy communal lifestyle in search of a breeding territory. Dispersal movements through

Table 3. Model selection for the data set of fledglings (Sub-1) including individual covariates and the quality of the natal territory. Models

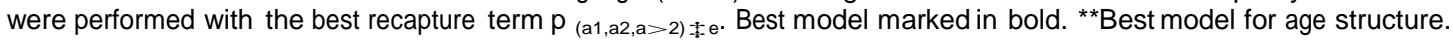

\begin{tabular}{|c|c|c|c|c|c|c|}
\hline No. & Model & $\mathrm{AICC}$ & DAICc & AICc weight & N. Par. & Deviance \\
\hline 1 & phi (a1, a2, a3, a4, a5, a>5) * r & 2318.18 & 17.89 & 0.0001 & 16 & 2285.70 \\
\hline 2 & phi $(a 1, a 2, a 3, a 4, a 5, a>5) \neq r$ & 2309.07 & 8.78 & 0.0102 & 11 & 2286.84 \\
\hline 3 & phi $(a 1=a 2, a 3, a 4, a 5, a>5) \neq r$ & 2307.77 & 7.48 & 0.0195 & 10 & 2287.58 \\
\hline 4 & phi $(a 1=a 2, a 3=a 4, a 5, a>5) \neq r$ & 2306.94 & 6.66 & 0.0295 & 9 & 2288.79 \\
\hline 5 & phi $(a 1=a 2, a 3=a 4, a>4) \neq r$ & 2305.39 & 5.10 & 0.0643 & 8 & 2289.26 \\
\hline 6 & phi $(a 1=a 2, a>2) \neq r$ & 2314.29 & 14.01 & 0.0007 & 7 & 2300.20 \\
\hline 7 & phi $(a 1=a 2, a 3=a 4, a>4) \neq b c \neq r$ & 2307.37 & 7.09 & 0.0238 & 9 & 2289.22 \\
\hline 8 & phi $(a 1=a 2, a 3=a 4, a>4) \neq n b r$ fled $\neq r$ & 2307.37 & 7.08 & 0.0239 & 9 & 2289.21 \\
\hline 9 & phi $(a 1=a 2, a 3=a 4, a>4) \neq N D V I$ terr $\neq r$ & 2300.29 & 0.00 & 0.8241 & 9 & 2282.13 \\
\hline 10 & phi $(a 1=a 2, a 3=a 4, a>4) \neq t \neq r$ & 2310.99 & 10.70 & 0.0039 & 22 & 2266.10 \\
\hline
\end{tabular}

ax: age class; e: recapture effort; r: ring effect; bc: body condition; nbr fled: mean number of fledglings raised in the territory; NDVI terr: NDVI in the natal territory at the year of birth; t: time effect. 
Table 4. Model selection for the full data set (Sub-2) including environmental and human pressure effects. The best recapture term, $\mathrm{p}_{(\mathrm{a} 1,}$ a2, $a>2) \neq g \neq e$, is used in all the models. Best models marked in bold. ${ }^{*}$ Best model for age structure.

\begin{tabular}{|c|c|c|c|c|c|c|}
\hline No. & Model & $\mathrm{AICc}$ & DAICc & AICc weight & N.Par. & Deviance \\
\hline 11 & phi $(a 1=a 2, a 3, a 4, a 5, a>5) \neq r$ & 4088.87 & 10.96 & 0.0023 & 11 & 1749.15 \\
\hline 12 & phi $\left(\begin{array}{l}(a 1=a 2, a 3, a 4, a 5, a>5) \neq r \\
(a)=a 3=a 4, a 5, \quad a>5) \neq r\end{array} * \star\right.$ & 4087.69 & 9.78 & 0.0041 & 10 & 1750 \\
\hline 13 & phi $\left(a_{1}=a 2, a 3=a 4, a>4\right) \neq r$ & 4090 & 12.09 & 0.0013 & 9 & 1754.33 \\
\hline 14 & phi $(a 1=a 2, a>2) \neq r$ & 4092.45 & 14.54 & 0.0004 & 8 & 1758.84 \\
\hline 15 & phi $(a 1=a 2, a 3=a 4, a 5, a>5, g) \neq r$ & 4089.49 & 11.58 & 0.0017 & 11 & 1749.76 \\
\hline 16 & phi $(a 1=a 2, a 3=a 4, a 5, a>5) \neq p o \neq r$ & 4088.39 & 10.48 & 0.0029 & 11 & 1748.67 \\
\hline 17 & phi $(a 1=a 2, a 3=a 4, a 5, a>5)^{\star}$ po $\neq r$ & 4088.64 & 10.73 & 0.0026 & 14 & 1742.82 \\
\hline 18 & phi $(a 1=a 2, a 3=a 4, a 5, a>5) \neq N D V \mid A f r \neq r$ & 4077.91 & 0 & 0.5464 & 11 & 1738.19 \\
\hline 19 & phi $(a 1=a 2, a 3=a 4, a 5, a>5) * N D V I A f r \neq r$ & 4193.56 & 115.65 & 0.0000 & 14 & 1847.73 \\
\hline 20 & phi ${ }_{(a 1=a 2, a 3=a 4, a 5, a>5) \neq N D V I} b r e \neq r$ & 4199.74 & 121.83 & 0.0000 & 11 & 1860.01 \\
\hline 21 & phi $(a 1=a 2, a 3=a 4, a 5, a>5) * N D V 1$ bre $=r$ & 4257.31 & 179.4 & 0.0000 & 14 & 1911.49 \\
\hline 22 & phi $\left({ }^{2} 1=a 2, a 3=a 4, a 5, a>5\right) \neq t \neq r$ & 4078.35 & 0.44 & 0.4385 & 24 & 1712.04 \\
\hline
\end{tabular}

ax: age class; e: recapture effort; r: ring effect; g: group of birds banded as adults; po: intensity of poisoning; NDVI Afr: NDVI in the African wintering grounds; NDVI bre: NDVI in the breeding area; t: time effect.

unknown areas or hostile matrixes are known to be costly for some insects, mammals and birds as they may increase their risk of death by accident, starvation, predation, or conspecific interactions (Yoder et al. 2004, Schtickzelle et al. 2006, Smith and Batzli 2006). Therefore, this unusual survival pattern (as far as we know not found in other bird species) could be related to costs associated to adulthood and recruitment into the breeding population. A similar pattern could be expected in other species in which the transition from the immature to the adult life involves important changes in spatial and resource use. More light will probably be shed on this topic with improvements in the knowledge of dispersal and recruitment phases in longlived territorial birds (Penteriani et al. 2005).

In our analysis we could not distinguish mortality from permanent emigration (Lebreton et al. 1992) and therefore the possibility exists that we overestimated mortality rates due to the presence of long-distance dispersers and vagrant adults captured with cannon nets (Le Gouar et al. 2008). However, we think that these effects would hardly explain the difference of about $15 \%$ in survival rates relative to younger age-classes by several reasons. First, the decline in apparent survival was already detected with the yearlings' data set (Sub-2) and we monitored a large area (about $250>125 \mathrm{~km}$ ) relative to the species dispersal patterns (median natal dispersal $=19.74 \mathrm{~km}$, range $=0-150 \mathrm{~km}$, $\mathrm{n}=26$; Grande et al. unpubl.). Second, the fact that no

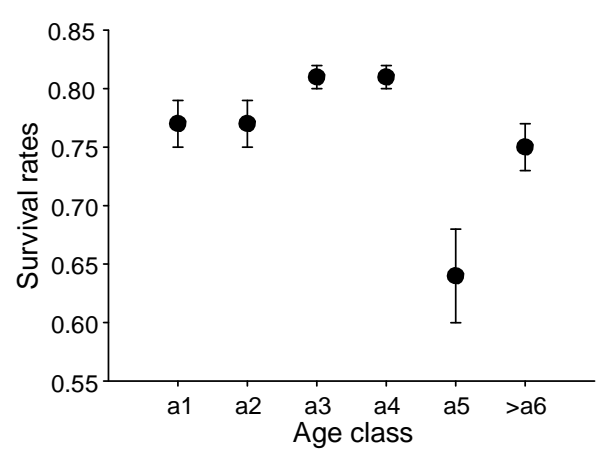

Figure 2. Age-dependent survival rates of Egyptian vultures according to model phi $(a 1=a 2, a 3=a 4, \quad a 5, \quad a>5) \neq r \quad p \quad(a 1, \quad a 2$, $\mathrm{a}>2) \neq \mathrm{g} \neq \mathrm{e}$. Only values from individuals marked with thick rings are shown. transient effect was detected in the group of birds marked as adults militates against the existence of high proportions of vagrant birds. Further, no marked bird was detected during regular surveys of territories outside the limits of our studied population. Finally, the number of empty territories in our studied population sharply increased during the study period (Grande 2006, Carrete et al. 2007) contrasting with an apparent stability of closer populations (D. Gómez and J. L. Lagares pers. comm.). Therefore, it appears that our marked birds had much higher opportunities of recruitment within our studied population than in the surrounding areas.

As expected, we did not find significant differences in survival rates between sexes. However, contrary to our predictions, there was not a relationship between body condition and survival rates of fledglings. We cannot ignore the possibility that this factor could operate at earlier stages of development through brood reduction (Donázar 1993, Mauck et al. 2004), or could be only detectable with very large data sets (Tavecchia et al. 2001). Alternatively, this result could be a consequence of the conservative life strategy previously described in other large, long-lived species, where juveniles may be adapted to strong variations in body mass imposed by feeding on unpredictable food resources (Donázar 1993, Stienen and Brenninkmeijer 2002), while breeding adults may fine-tune their investment on reproduction through the breeding season to counterbalance the needs of the chick during the caring period after fledgling (Ceballos and Donázar 1990, Stienen and Brenninkmeijer 2002).

Effects of ecological conditions in wintering and breeding areas on survival rates of migratory species

We found a marked and consistent positive relationship of ecological conditions in wintering areas on survival rates of Egyptian vultures regardless of their age and breeding status. As in other long distance trans-Saharan migrant species, positive covariation of primary productivity or rainfall on survival could be mediated by trophic resource availability (Szép 1995, Schaub et al. 2005, but see Forero et al. 2001). Wintering Egyptian vultures feed on domestic ungulates (mainly sheep and goat), but also on small wild 


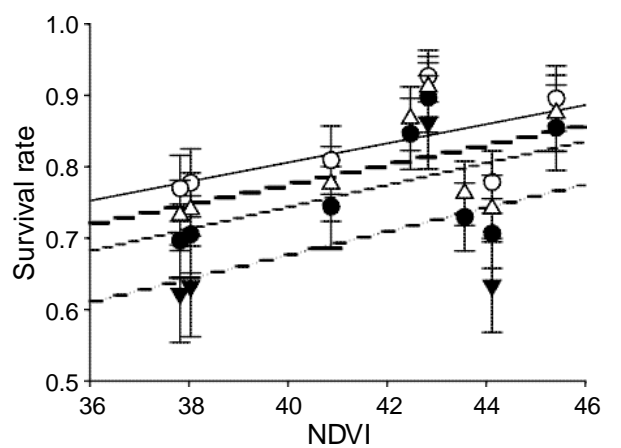

Figure 3. Relationship between NDVI index and survival estimates in Egyptian vultures (only birds marked with thick rings are shown). Symbols are estimated values (9SE) from the time-dependent model phi (a1=a2, a3=a4, a5, a>5) $\neq \mathrm{t} \neq \mathrm{r} P$ (a1, a2, $\mathrm{a}>2) \neq \mathrm{g} \neq \mathrm{e}$ (unconstrained by NDVI values) against actual NDVI values during time intervals. Values and regression lines for birds of 1-2 (black circles-dotted line), 3-4 (white triangles-solid line), 5 (black triangles-dotted-dashed line) and $>5$ years old (white circles-dashed line) are shown.

prey and insects (Grande et al. unpubl.), which are more abundant in wet than in dry years (Todd et al. 2002, Schaub et al. 2005, Holmgren et al. 2006). Domestic herds are transhumant and in the driest years are driven to the south to reach the more humid African areas of Senegal and Mali. Therefore, both domestic and wild food sources must be scarce for scavenging birds in dry winters. It is possible, however, that in dry years wintering scavenging birds must follow domestic herds to the southern countries, where the human population is larger and direct and indirect persecution stronger. Indeed, hunting and poisoning is thought to be responsible for the rarefaction of vultures and other large raptors through western Africa during the last decades (Rondeau and Thiollay 2004).

The positive correlation of primary productivity of the natal territory the year of birth and juvenile survival could reflect the relevance of the local conditions in which an individual is raised, in spite of the weak relationship between fledgling body mass and survival (above). Variations in rearing conditions, due to either parental or environmental quality, can result in offspring of different quality that should be reflected in individual fitness (Lindström 1999). These variations can have a long-lasting effect, acting on the long term survival prospects of the bird all through its life (Reid et al. 2006) or can only have an immediate effect, affecting survival prospects during the first months or years of life (Spear and Nur 1994) like seems to be the case in the Egyptian vulture. The energetic content and nutritional quality of food fed to chicks are both determinants of physiological stress and immunocompetence (Kitaysky et al. 1999, Alonso-Alvarez and Tella 2001), which may affect survival prospects (Tella et al. 2000, Blas et al. 2007). Thus, migratory birds born in richer environments in a determined year would probably be healthier (something not simply reflected by body mass), what should give them more possibilities of successfully cope with the long migration journey and to survive their first winters at their wintering grounds.

For breeding birds, we found an additional positive relationship between the quality of the breeding territory measured in terms of reproductive output and survival rates. This covariation might arise because high quality territories have high availability of resources and thus breeders have reduced physiological costs linked to breeding activities and self-maintenance (Oro and Furness 2002, Davis et al. 2005), or because high quality territories are less risky (lower predation, poison use, less dangerous electric lines and wind farms, etc.). The fact that breeding success and territory extinction was related in this species with classic habitat variables and poison use (Grande 2006, Carrete et al. 2007) suggests that both interpretations of this result are valid. If we consider habitat quality from a demographic point of view (Johnson 2007), the Egyptian vulture population from the Ebro Valley would be structured in territories of high and low quality in which the first contribute with much more fledglings to the pool of potential breeders while the second act as a sink of breeding individuals (Serrano et al. 2005). Given that conservation funds are usually limited our results suggest that while general conservation measures are implemented to improve the general health of the population, strong efforts should be devoted to protect those territories of higher quality (Sergio and Newton 2003).

Importantly, mean survival of territorial Egyptian vultures was substantially lower than that estimated for other healthier populations of long-lived raptors (from 0.94 to 0.99; Ferrer and Calderón 1990, Green et al. 1996, Real and Mañosa 1997, Whitfield et al. 2004, Le Gouar et al. 2008). Moreover, our survival estimates were lower than those found in a small but stable population of the same

Table 5. Model selection for the breeding adult data subset (Sub-3). Modelling was performed with a constant recapture term ( $p_{c t} ; 0.949$ 0.02). Best model marked in bold.

\begin{tabular}{|c|c|c|c|c|c|c|}
\hline No. & Model & $\mathrm{AICc}$ & DAICc & AICc weight & N.Par. & Deviance \\
\hline 23 & phi $_{\mathrm{ct}}$ & 326.546 & 9.892 & 0.005 & 2 & 322.499 \\
\hline 24 & $\mathrm{Phi}_{\mathrm{t}}$ & 321.24 & 4.586 & 0.068 & 12 & 295.98 \\
\hline 25 & Phi NDVI Afr & 319.649 & 2.995 & 0.150 & 3 & 313.555 \\
\hline 26 & Phi nbr fled & 327.152 & 10.498 & 0.004 & 3 & 321.058 \\
\hline 27 & $\mathrm{Phi}$ po & 327.849 & 11.195 & 0.002 & 3 & 321.755 \\
\hline 28 & Phi NDVI terr & 328.375 & 11.721 & 0.002 & 3 & 322.28 \\
\hline 29 & Phi NDVI bre & 328.55 & 11.896 & 0.002 & 3 & 322.46 \\
\hline 30 & phi NDVI Afr $\neq$ nbr fled & 316.654 & 0 & 0.672 & 4 & 308.498 \\
\hline 31 & Phi NDVI Afr * nbr fled & 320.562 & 3.908 & 0.095 & 5 & 312.597 \\
\hline
\end{tabular}

ct: constant; t: time effect; NDVI Afr: NDVI in the African wintering grounds; nbr fled: mean number of fledglings raised in the territory; po: intensity of poisoning; NDVI terr: NDVI in the territory; NDVI bre: NDVI in the breeding area. 
species from the Canary Islands (0.90, from only nine individuals in a four year period; Donázar et al. 2002). Although it could be argued that this low survival could be an artefact of permanent emigration (Lebreton et al. 1992), it should be noted that breeding dispersal in this species is extremely low (less than $5 \%$ of the marked adults monitored in successive years dispersed to a different breeding territory and this dispersals were always of short distance: median $=2.43 \mathrm{~km}$, rank $0.44-10.78 \mathrm{~km})$. According to population ecology theory (Newton 1979, Sæther and Bakke 2000), low survival values in older age categories in a long-lived species could by itself produce sharp population declines such as the one suffered by our study population during the study period (Carrete et al. 2007). The use of poison to control predators increased dramatically in Spain after the irruption of the rabbit haemorrhagic disease that decimated Spanish rabbit populations in the early 1990s, and it partially explained the temporal patterns of territory extinction of Egyptian vultures at different geographical scales (Grande 2006, Carrete et al. 2007) as well as the decline of other opportunistic scavenging raptors (Villafuerte et al. 1998). Therefore, we expected poison use to be the main factor determining survival, but we failed to detect a clear statistical effect of this variable. Being that the use of poison is an illegal and thus largely covert activity (Whitfield et al. 2004), this lack of effect probably reflects the difficulty of obtaining an adequate and unbiased measure of poisoning rather than an actual lack of effect of persecution on survival.

\section{Conclusions}

The strong bias in previous studies of survival rates in longlived bird species towards colonial birds, as well as the difficulty of obtaining reliable data on the survival of birds on immature dispersing stages, could have obscured the relevance of behavioural traits linked to dispersal, prospecting, and acquisition of breeding territories on demography of territorial species. Long-lived birds are usually faithful to their breeding territories through their life-span (low breeding dispersal, Newton 1979), so first choice and timing of breeding habitat should be particularly relevant in terms of fitness (i.e. reproduction and survival). Thus, individuals should invest in searching for high quality areas even when longer dispersal and prospecting periods can reduce their survival likelihood (Kokko and Sutherland 1998). This tradeoff could affect the recruitment pattern of these species, thus promoting delayed recruitment to the breeding population well beyond sexual maturity, even in the presence of empty territories (as found in this study) if they are of low quality.

Our results also highlight the relevance that may have ecological conditions faced by migratory species in both their wintering and breeding quarters, as has been recently shown for another long-lived bird (Schaub et al. 2005). In this context, it would be necessary to identify whether the effects of wintering conditions on survival are linked to food availability that may be heavily impacted by climatic global change, or to human pressure, which seems to be increasing in the Sahel in recent decades (Rondeau and Thiollay 2004). As conservation of most Eurasian migratory species could be also dependent on the circumstances faced in both wintering and breeding quarters, identifying their relative roles is critical for applying appropriate conservation measures.

Acknowledgements - We want to sincerely thank to all the people who, along the study period, contributed to marking and reading effort, especially I. Luque, M. de La Riva, A. Cortés, D. Campión, E. Ursúa, F. H. Fernández, R. López, A. Gajón, D. Gómez, J. M. Aguilera, J. A. Pinzolas, A. Bueno, J. C. Albero, J. M. Canudo, C. Usieto, J. Sanz, J. L. Ruiz, J. L. Rivas, E. Alcaine, J. L Lagares, P. Martínez, A. Legaz, P. Oliva, A. Pastor and J. A. Pérez-Nievas. C. Cano, environmental agents of Navarra, and the staff of the wildlife rehabilitation centre of La Alfranca (Gobierno de Aragón) provided information on poisoning events. Remote Sensing Laboratory of Univ. of Valladolid provided the time series of NDVI composites from Spain, fully geocorrected and ready to use. This study was partially supported by the Gobierno de Aragón and the Gobierno de Navarra. The staff of the Bardenas Reales Natural Park provided some logistical support and permited to mark the birds. A Juan de la Cierva, I3P and Ramón y Cajal post-doc contracts from the Spanish Education and Science Ministry supported JMG, MC, DS and GT, respectively.

\section{References}

Alonso-Alvarez, C. and Tella, J. L. 2001. Effects of experimental food restriction and body-mass changes on avian T-cell mediated immune response. - Can. J. Zool. 79: 101-105.

Altwegg, R. et al. 2003. Variation and covariation in survival, dispersal and population size in barn owls, Tyto alba. - J. Anim. Ecol. 72: 391-399.

BirdLife International. 2004. Birds in the European Union: a status assessment. - BirdLife Int., Wageningen, the Netherlands.

Blas, J. et al. 2007. Stress response during development predicts fitness in a wild, long-lived vertebrate. - Proc. Natl Acad. Sci. USA 104: 8880-8884.

Breitwisch, R. 1989. Mortality patterns, sex ratios, and parental investment in monogamous birds. - Curr. Ornithol. 6: 1-50.

Burnham, K. P. and Anderson, D. R. 1998. Model selection and inference: a practical information-theoretic approach. - Springer.

Carrete, M. et al. 2006. Components of breeding performance in two competing species: habitat heterogeneity, density-dependence and parental age. - Oikos 112: 680-690.

Carrete, M. et al. 2007. Habitat, human pressure and social behaviour: partialling out factors affecting territory extinction in the Egyptian vulture. - Biol. Conserv. 136: 143-154. Ceballos, O. and Donázar, J. A. 1990. Parent-offspring conflict during the post-fledging period in the Egyptian vulture Neophron percnopterus (Aves, Accipitridae). - Ethology 85: 225-235.

Choquet, R. et al. 2002. U_Care: user's guide 1.4. CEFE-CNRS, Montpellier, France. <ftp://ftp.cefe.cnrs-mop.fr/biom/SoftCRP.

Conover, M. R. et al. 2000. Costs and benefits of sub adult plumage in mute swans: testing the hypotheses for the 
evolution of delayed plumage maturation. - Am. Nat. 156: 193-200.

Coulson, T. et al. 2001. Age, sex, density, winter weather and population crashes in Soay sheep. - Science 292: 1528 -1531.

Davis, S. E. et al. 2005. Food availability affects adult survival as well as breeding success of parasitic jaegers. - Ecology 86: 1047-1056.

del Hoyo, J. et al. 1994. Handbook of the birds of the World. Vol. 2: New World vultures to Guinea fowls. - Lynx Edicions, Barcelona.

Donázar, J. A. 1993. Iberian vultures; biology and conservation. - J. M. Reyero, Madrid.

Donázar, J. A. et al. 2002. Conservation status and limiting factors in the endangered population of Egyptian vulture (Neophron percnopterus) in the Canary Islands. - Biol. Conserv. 107: 8997.

Ellegren, H. 1996. First gene on the avian W chromosome (CHD) provides a tag for universal sexing of non-ratite birds. - Proc. R. Soc. Lond. B 263: 1635-1641.

Ferrer, M. and Calderón, J. 1990. The Spanish imperial eagle Aquila adalberti in Doñana National Park: a study of population dynamics. - Biol. Conserv. 51: 151-161.

Forero, M. G. et al. 2001. Annual survival rates of adult rednecked nightjars (Caprimulgus ruficollis). - Ibis 143: 273-277.

Forsman, D. 1999. The raptors of Europe and the Middle East: a handbook of field identification. - T. and A. D. Poyser. Franklin, A. B. et al. 2000. Climate, habitat quality, and fitness in northern spotted owl populations in northwestern California. - Ecol. Monogr. 70: 539-590.

Gaillard, J.-M. et al. 1998. Population dynamics of large herbivores: variable recruitment with constant adult survival.

- Trends Ecol. Evol. 13: 58-63.

Grande, J. M. 2006. Natural and human induced constrains on the population dynamics of long-lived species: the case of the Egyptian vulture (Neophron percnopterus) in the Ebro Valley. PhD thesis. - Univ. of Seville, Spain.

Green, R. E. et al. 1996. Long-term viability of the re-introduced population of the white-tailed eagle Haliaeetus albicilla in Scotland. - J. Appl. Ecol. 33: 357-368.

Harris, M. P. et al. 1992. The post-fledgling survival of young guillemots Uria aalge in relation hatching date and growth. - Ibis 134: 335-339.

Hirshfield, M. F. and Tinkle, D. W. 1975. Natural selection and the evolution ofreproductive effort. - Proc. Natl Acad. Sci. USA 72: 2227-2231.

Holmgren, M. et al. 2006. Extreme climatic events shape arid and semiarid ecosystems. - Front. Ecol. Environ. 4: 87-95.

Johnson, M. D. 2007. Measuring habitat quality: a review. - Condor 109: 489-504.

Kauffman, M. J. et al. 2003. Estimation of habitat-specific demography and growth for peregrine falcons in California. - Ecol. Appl. 13: 1802-1816.

Kitaysky, A. S. et al.1999. The adrenocortical stress-response of black-legged kittiwake chicks in relation to dietary restrictions. - J. Comp. Physiol. B 169: 303-310.

Kokko, H. and Sutherland, W. J. 1998. Optimal floating and queuing strategies: consequences for density dependence and habitat loss. - Am. Nat. 152: 354-366.

Lebreton, J. D. et al. 1992. Modeling survival and testing biological hypotheses using marked animals: a unified approach with case studies. - Ecol. Monogr. 62: 67-118.

Le Gouar, P. et al. 2008. Roles of survival and dispersal in reintroduction success of griffon vulture (Gyps fulvus). - Ecol. Appl. 18: 859-872.

Lindström, J. 1999. Early development and fitness in birds and mammals. - Trends Ecol. Evol. 14: 343-348.
Magrath, R. D. 1991. Nestling weight and juvenile survival in the blackbird, Turdus merula. - J. Anim. Ecol. 60: 335-351.

Mauck, R. A. et al. 2004. Age-specific reproductive success: evidence for the selection hypothesis. - Evolution 58: 880885.

Newton, I. 1979. Population ecology of raptors. - T. and A. D. Poyser.

Oro, D. and Furness, R. W. 2002. Influences of food availability and predation on survival of kittiwakes. - Ecology 83: 25162528.

Penteriani, V. et al. 2005. Floater survival affects population persistence: the role of prey availability and environmental stochasticity. - Oikos 108: 523-534.

Real, J. and Mañosa, S. 1997. Demography and conservation of western European Bonelli's eagle populations. - Biol. Conserv. 79: $59-66$

Reed, J. M. et al. 1999. Informed dispersal: prospecting by birds for breeding sites. - Curr. Ornithol. 15:189-259.

Reid, J. M. et al. 2006. Spatial variation in demography and population growth rate: the importance of natal location. $-\mathrm{J}$. Anim. Ecol. 75: 1201-1211.

Rondeau, G. and Thiollay, J. M. 2004. West African vulture decline. - Vulture News 51: 13- 33.

Sæther, B. E. and Bakke, O. 2000. Avian life history variation and contribution of demographic traits to the population growth rate. - Ecology 81: 642-653.

Schaub, M. et al. 2005. Variation of primary production during winter induces synchrony in survival rates in migratory white storks Ciconia ciconia. - J. Anim. Ecol. 74: 656-666.

Schtickzelle, N. et al. 2006. Dispersal depression with habitat fragmentation in the bog fritillary butterfly. - Ecology 87: 1057-1065.

Seoane, J. et al. 2003. The effects of land use and climate on red kite distribution in the Iberian Peninsula. - Biol. Conserv. 111: 401-414.

Sergio, F. and Newton, I. 2003. Occupancy as a measure of territory quality. - J. Anim. Ecol. 72: 857-865.

Serrano, D. et al. 2005. Colony size selection determines adult survival and dispersal preferences: Allee effects in a colonial bird. - Am. Nat. 166: 12-21.

Smith, J. E. and Batzli, G. O. 2006. Dispersal and mortality of prairie voles in fragmented landscapes: a field experiment (Microtus ochrogaster). - Oikos 112: 209-217.

Spear, L. and Nur, N. 1994. Brood size, hatching order and hatching date: effects on four life-history stages from hatching to recruitment in western gulls. - J. Anim. Ecol. 63: 283-298.

Stearns, S. C. 1992. The evolution of life histories (Martin, T. E. Ed.). - Oxford Univ. Press.

Stienen, E. W. M. and Brenninkmeijer, A. 2002. Variation in growth in sandwich tern chicks Sterna sandvicensis and the consequences for pre- and post-fledging mortality. - Ibis 144: 567-576.

Sutherland, W. J. 2000. The conservation handbook: research, management and policy. - Blackwell.

Szép, T. 1995. Relationship between West African rainfall and the survival of central European sand martins Riparia riparia. - Ibis 137: 162-168.

Tavecchia, G. et al. 2001. Sex- and age-related variation in survival and cost of first reproduction in greater flamingos. - Ecology 82: $165-174$

Tavecchia, G. et al. 2008. Living close, doing differently: smallscale asynchrony in demography of two species of seabirds. - Ecology 89: 77-85.

Tella, J. L. et al. 2000. The T-cell-mediated immune response and return rate of fledgling American kestrels are positively correlated with parental clutch size. - Proc. R. Soc. Lond. B 267: 891-895. 
Todd, M. C. et al. 2002. Brown locust outbreaks and climate variability in southern Africa. - J. Appl. Ecol. 39: 31-42.

van de Pol, M. et al. 2006. A silver spoon for a golden future: long-term effects of natal origin on fitness prospects of oystercatchers (Haematopus ostralegus). - J. Anim. Ecol. 75: 616-626.

van der Jeugd, H. P. and Larsson, K. 1998. Pre-breeding survival in barnacle geese Branta leucopsis in relation to fledgling characteristics. - J. Anim. Ecol. 67: 953-966.

Villafuerte, R. et al. 1998. Extensive predator persecution caused by population crash in a game species: the case of the red kites and rabbits in Spain. - Biol. Conserv. 84: 181-188.
White, G. C. and Burnham, K. P. 1999. Program MARK: survival estimation from populations of marked animals. - Bird Study 46: S120-S139.

Whitfield, D. P. et al. 2004. The effects of persecution on age of breeding and territory occupation in golden eagles in Scotland. - Biol. Conserv. 118: 249-259.

Yoder, J. M. et al. 2004. The cost of dispersal: predation as a function of movement and site familiarity in ruffed grouse. - Behav. Ecol. 15: 469-476. 